\title{
Climate variability and vertical advection of nitrates in the Gulf of St. Lawrence, Canada
}

\author{
Jacques Plourde*, Jean-Claude Therriault \\ Department of Fisheries and Oceans, Ocean Sciences Branch, Maurice Lamontagne Institute, PO Box 1000,850 de la Mer, \\ Mont-Joli, Quebec G5H 3Z4, Canada
}

\begin{abstract}
Using a modeling approach, we constructed a time series to examine interannual variability in the spring nitrate concentrations in the surface layer of the Gulf of St. Lawrence (GSL) for the period 1947 to 2000. This 2-step modeling approach used the lower boundary of the cold intermediate layer (CIL), a persistent summer characteristic of the temperature profiles in the GSL, to infer interannual variations in the depth of the winter mixed layer. Using a linear model describing the distribution of nitrates at intermediate depths, we estimated a time series of spring nitrate concentration in the surface waters of the GSL for the period 1947 to 2000. This early spring time series showed interannual fluctuations in nitrate concentrations of about 1 order of magnitude, attributable to variability in winter convection. Such variability in the spring nitrate availability should have a significant impact on the ecosystem. Some elements that should be taken into account in any future attempt to validate this estimated nitrate time series are discussed.
\end{abstract}

KEY WORDS: Gulf of St. Lawrence $\cdot$ Climate $\cdot$ Nitrates $\cdot$ Temperature

Resale or republication not permitted without written consent of the publisher

\section{INTRODUCTION}

Many attempts to relate changes in the abundance of marine resources with oceanographic factors have been made in the past. In a review, Mann (1993) concluded that strong circumstantial evidence indicated that large-scale oceanographic processes have a major influence on the rise and fall of fish stocks worldwide. In order to reduce the uncertainty associated with the correlative nature of this evidence, he proposed an approach based on a search for mechanisms linking physical processes to biological consequences and testing for their occurrence in the ecosystems supporting the stocks of interest. With respect to this latter point, an understanding of the processes that govern phytoplankton productivity in the ocean is an obvious starting point, since available food energy in the ecosystem largely depends on autotrophic phytoplankton.

Phytoplankton productivity in the sea is usually limited by light and nutrients (Dugdale \& Wilkerson 1992). These 2 basic requirements for photosynthesis generally display contrasting vertical gradients, with light availability decreasing from the surface to the bottom, and nutrient availability increasing from the bottom to the surface. Among nutrients, nitrogen is most often considered the limiting factor in oceanic waters (Platt et al. 1989, Yentsch 1990, Barber 1992). Many physical processes have been suggested to control the vertical advection of nutrients at different time and space scales. In eutrophic mid-latitude regions, the depth of the annual vertical winter mixing is believed to be a key factor (Barber 1992). At these latitudes, deep winter mixing entrains high nutrient concentrations in the surface layer, which then becomes isolated from deeper waters by the seasonal thermohalocline, a zone of rapid changes in the vertical distribution of temperature and salinity. Barber (1992) suggested that this process could be a major source of interannual variability in nutrient abundance. However, he also pointed out that only a few time series showing interannual variability in nutrient abundance exist in the literature. One such example is the study of Nicholls (1998), who showed that during a $19 \mathrm{yr}$ record of the Lake Huron outflow, phosphorus concentration was 
negatively correlated with the extent of winter ice cover in the Great Lakes. Petrie \& Yeats (2000) also found that the interannual variability in nitrate on the Scotian Shelf was related to changes in water masses over a 40 yr period.

The Gulf of St. Lawrence (GSL) is a strongly stratified semi-enclosed sea located in eastern Canada. A prominent feature of the water column of the GSL is the presence of a cold intermediate layer (CIL) with temperature characteristics that persist through the summer (Banks 1966). The CIL is formed during the winter months when the surface waters are cooled to near-freezing temperatures (down to $\sim 100 \mathrm{~m}$ in places, depending on time of year). This mixing process contributes to the surface water replenishment of nitrates in the GSL by vertical advection of higher nutrient concentrations from deeper depths. The formation of a strong thermohalocline due to the spring-summer warming of the surface waters then isolates the cold waters at intermediate depths throughout the summer and early fall months. Therefore, the CIL is largely the product of in situ winter cooling, although a significant fraction of its volume may also come from Labrador shelf waters entering the GSL through the Strait of Belle Isle (Banks 1966, Koutitonsky \& Bugden 1991, Drinkwater 1996, Gilbert \& Pettigrew 1997, Therriault et al. 2002).

The GSL is characterized by relatively high and variable fish and invertebrate productivity and it would be of great interest to discover mechanisms linking this variable productivity with interannual nitrate availability. Unfortunately, a time series of nitrate concentration was also lacking for the GSL. However, after examining the vertical characteristics of temperature and nitrate profiles in the GSL, we concluded that it was possible to use an indirect approach to construct a retrospective times series of nitrate concentrations in early spring for the period 1947 to 2000, and to use these to infer the retrospective interannual variability of spring primary production in the GSL. We describe the approach that was used to construct this nitrate time series and discuss some of the elements that should be taken into account in the future to test the validity of this 'estimated' nitrate time series.

\section{MATERIALS AND METHODS}

Gulf of St. Lawrence. Yeats (1988) examined the vertical distribution of nutrients in the GSL. Among summer consistencies in the vertical distribution of nitrate concentration he found a fairly rapid increase from low levels in the surface waters to higher levels in the 75 to $150 \mathrm{~m}$ depth range, and a much more gradual increase from $150 \mathrm{~m}$ to the bottom. At the onset of spring, nutri- ents are distributed fairly uniformly throughout the top $100 \mathrm{~m}$ of the water column, but the surface layer becomes rapidly nutrient-depleted as the spring bloom of phytoplankton develops. Nutrients then remain at relatively low levels throughout the summer-early fall months, until new replenishment takes place due to winter convection. In his review of the chemical oceanography of the GSL, Strain (1988) pointed out that one important limitation of the existing nutrient data is that the GSL has not been sampled sufficiently frequently in time and space to allow proper characterization of the important scales of variability. This implies that an assessment of interannual variability of nutrient availability in the GSL is not possible unless it is based on other co-varying properties in the water column, such as temperature, for which a sufficiently long time series of data already exists (Bugden et al. 1981).

Model approach. We examined the possibility that the strong gradients in the vertical distribution of both nitrates and temperature at intermediate depths in the GSL could be used to develop a nitrate-temperature model to assess interannual variability in nutrient abundance. The rationale behind our approach was based on the possibility of using persistent temperature characteristics of the CIL in the GSL to infer the depth of the previous winter mixing. Then, using a linear model describing the distribution of nitrates at intermediate depths, it would be possible to estimate the nitrate concentration in the surface layer in early spring, prior to the phytoplankton bloom.

Our 2-step model approach was based on 2 assumptions: (1) it is possible to model the spatio-temporal distribution of nitrate at intermediate depths in order to convert the depth of the winter mixed layer into nitrate concentration; (2) it is possible to infer the depth of the winter mixed layer from the lower boundary of the CIL.

Data. The spatial domain of the model in the GSL (Fig. 1) extends from the Lower St. Lawrence Estuary $\left(70^{\circ} \mathrm{W}\right)$ to the Strait of Belle Isle $\left(56^{\circ} 41^{\prime} \mathrm{W}\right)$ and to the Cabot Strait (boundaries of Subareas 1 and 2 in Petrie et al. 1996). Temperature and nitrate data used were restricted to the period 1947 to 2000 .

We used vertical profiles of temperature from the Climate Database at the Bedford Institute of Oceanography (Fisheries and Oceans, Dartmouth, Nova Scotia) and from the Oceanographic Data Management System of the Maurice Lamontagne Institute (Fisheries and Oceans, Mont-Joli, Quebec). Additional temperature profiles were kindly provided by J. Landry of the Maurice Lamontagne Institute. The spatial resolution of the temperature database was set to Latitude $0.02^{\circ}$ and Longitude $0.03^{\circ}(\sim 3 \mathrm{~km})$ with a temporal resolution of $1 \mathrm{~d}$. In those cases where replicate profiles were collected at a given location for a given day, only 1 profile was used in the analyses. The resulting temperature 


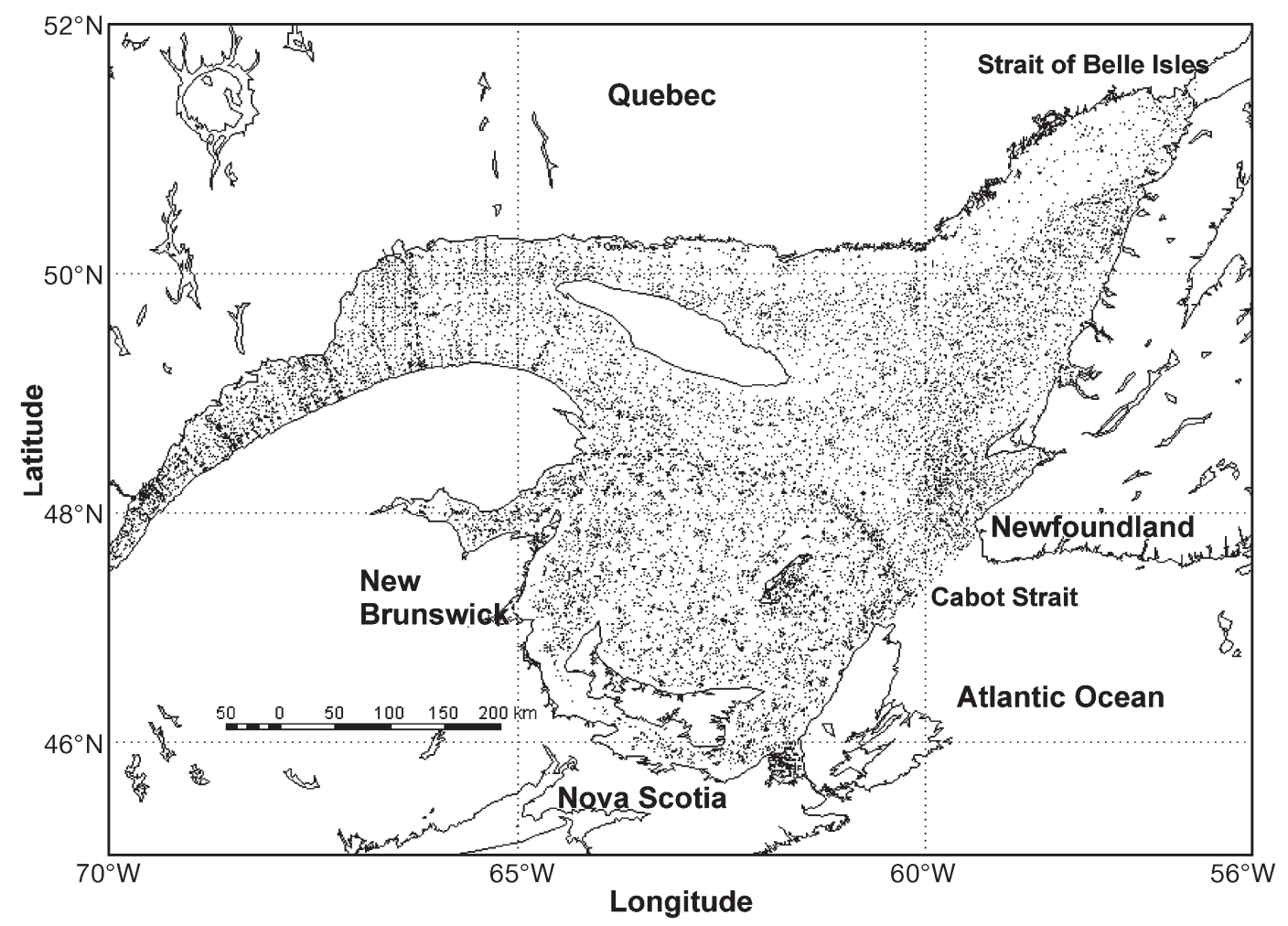

Fig. 1. Gulf of St. Lawrence, showing locations (dots) of all individual temperature profiles available for analysis

database consisted of 41441 vertical profiles collected at discrete depths or using continuous profilers.

Nitrate data were provided by Peter Strain of the Bedford Institute of Oceanography (Fisheries and Oceans, Dartmouth) and consisted of 8569 observations collected within the model domain between 1971 and 1997 .
Table 1. Stepwise multiple regression analysis of nitrate concentration from 30 to $225 \mathrm{~m}$ layer in Gulf of St. Lawrence. Independent variables included in the model specification are depth, latitude, longitude and month. $\mathrm{N}=2371$

\begin{tabular}{|llccrc|}
\hline Step & Variable & Partial $^{2}$ & Model $\mathrm{R}^{2}$ & \multicolumn{1}{c}{$F$} & $\mathrm{p}>F$ \\
\hline 1 & Depth & 0.6024 & 0.6024 & 3589.93 & 0.0001 \\
2 & Longitude & 0.1153 & 0.7178 & 967.79 & 0.0001 \\
3 & Month & 0.0010 & 0.7188 & 8.79 & 0.0031 \\
4 & Latitude & 0.0009 & 0.7197 & 7.64 & 0.0057 \\
\hline
\end{tabular}

\section{RESULTS}

\section{Predictive model of nitrate concentrations}

A linear model describing the spatio-temporal distribution of nitrate at intermediate depths in the GSL was constructed. A total of 2371 observations made in the intermediate layer (between 30 and $225 \mathrm{~m}$ ) from May to November (inclusive) were extracted from the database and subjected to stepwise multiple regression analysis (SAS Institute 1991) using nitrate concentration as the dependent variable and the spatio-temporal variables depth, latitude, longitude and month as independent variables. The results of this analysis indicated that the nitrate concentration in the intermediate layer could effectively be predicted (as indicated by the model's $\mathrm{R}^{2}$ ) from knowledge of depth (by far the most important predictor, as indicated by the partial $\mathrm{R}^{2}$ ), latitude, longitude and month (Table 1). The nitrate concentration $\left(\mathrm{NO}_{3}\right)$ in the depth layer between 30 and $225 \mathrm{~m}$ could then be predicted by:

$$
\begin{aligned}
\mathrm{NO}_{3}= & -44.5613+0.0876 \text { depth }-0.5758 \text { longitude } \\
& +0.0866 \mathrm{mo}+0.2035 \text { latitude }
\end{aligned}
$$

where $\mathrm{NO}_{3}$ is in $\mu \mathrm{M}$, depth in $\mathrm{m}$, longitude in ${ }^{\circ} \mathrm{W}$, latitude in ${ }^{\circ} \mathrm{N}$ and mo is month of the year. The negative coefficient of longitude and the positive coefficient of latitude in Eq. (1) are consistent with the spatial gradients reported by Steven (1974), indicating a general increase in nitrate concentration in northward and westward directions, respectively. The positive coefficient for month suggests the existence of diffusive 
physical processes and/or biological remineralization processes following winter convection. The validity of the model was tested using various methods, including the assessment of the underlying assumptions of the regression analysis and cross-validation techniques (Stevens 1992), and all of these (not shown) supported the general validity of Eq. (1).

\section{Detecting lower boundary of CIL}

A total of 30331 temperature profiles collected between May and November, and comprising at least 10 discrete observations each, were extracted from the database. Criteria based on the vertical resolution of the temperature profile, the general distribution of temperature over depth and the maximum sampled depth were then developed to allow the detection of the lower boundary of the CIL in these profiles. For each temperature profile we determined the minimum temperature of the profile $\left(T_{\min }\right)$, the temperature at the greatest sampled depth $\left(T_{Z_{\max }}\right)$, the greatest sampled depth $\left(Z_{\max }\right)$, the depth of the minimum temperature $\left(Z_{T_{\min }}\right)$ and the depth of the observation following the minimum temperature in the vertical profile $\left(Z_{T_{\text {min+1 }}}\right)$ (Fig. 2). We then computed $\Delta T$, the difference between

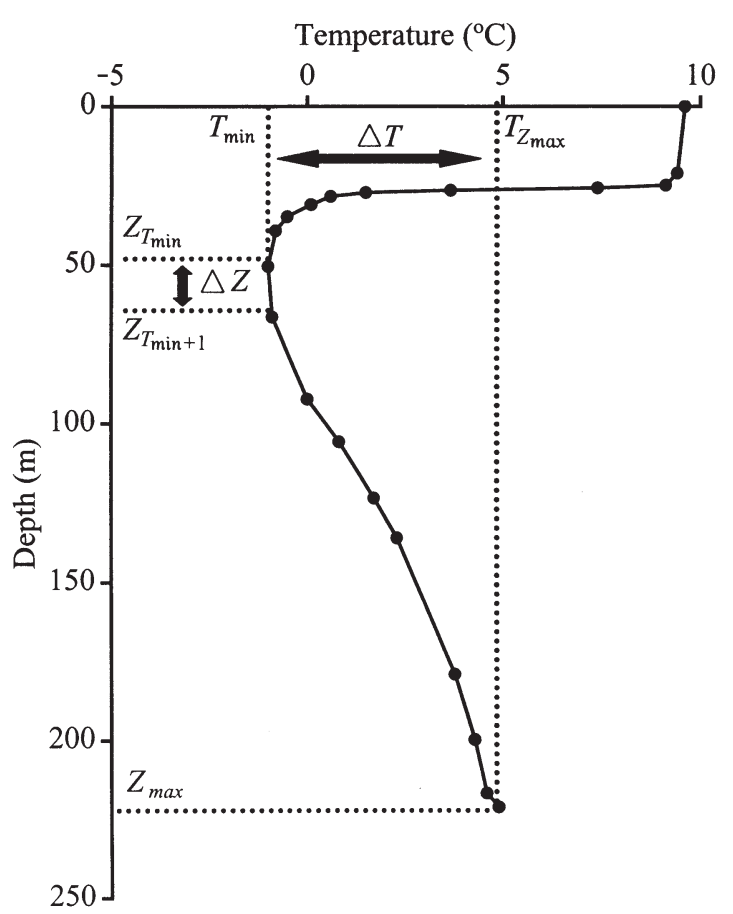

Fig. 2. Vertical profile of temperature showing variables used to detect lower boundary of cold intermediate layer. $T_{\min }$ : minimum temperature of profile; $T_{Z_{\max }}$ : temperature at greatest sampled depth; $Z_{T_{\min }}$ : depth of minimum temperature; $\Delta T$ : difference between $T_{Z_{\max }}$ and $T_{\min }$
$T_{Z_{\max }}$ and $T_{\min }$, and $\Delta Z$, the difference between $Z_{T_{\min }}$ and $Z_{T_{\min +1}}$. Some 8237 temperature profiles with $\Delta T$ values less than $1.0^{\circ} \mathrm{C}$ and $\Delta Z$ values $>30 \mathrm{~m}$ were subsequently rejected on the ground of incapacity to detect the intermediate layer. We also rejected 9976 other temperature profiles that did not allow the detection of the lower boundary of the CIL because $Z_{T_{\min }}$ was equal to $Z_{\max }$. Some 23 other temperature profiles displaying unusual values for at least 1 of the variables were also rejected. The remaining 12095 profiles were then assumed to have a well-defined CIL for which the lower boundary of the intermediate layer could be clearly detected. This data bank was used to construct the time series of the winter mixed layer depth.

\section{Time series of depth of winter mixed layer}

The best estimate of the depth of the winter mixed layer derived from the vertical temperature profiles would obviously have been achieved using the greatest depth at which temperature was closest to freezing point $\left(\sim-1.8^{\circ} \mathrm{C}\right)$. However, use of this criterion to infer the depth of the winter mixed layer from summer temperature profiles is practically impossible because of the seasonal erosion of the CIL (Banks 1966). Since the $0^{\circ} \mathrm{C}$ isotherm is commonly used to define the CIL in the NW Atlantic (Drinkwater 1996), the greatest depth of the $0^{\circ} \mathrm{C}$ isotherm $\left(Z_{0}\right)$ appeared to be the most acceptable estimator of the depth of the winter mixed layer.

Our database contained numerous temperature profiles with a well-defined CIL for which $Z_{0}$ could not be determined because $T_{\min }$ was $>0^{\circ} \mathrm{C}$ (Fig. 3). The frequency of occurrence of such profiles is yeardependent as indicated by the time series of $T_{\min }$ for the 12095 temperature profiles with a well-defined CIL (Fig. 4). For the years 1947 to 2000, most $T_{\min }$ ranged between -0.7 and $0.2^{\circ} \mathrm{C}$ (25th and 75 th percentiles, respectively), with a mean of $-0.21^{\circ} \mathrm{C}$.

Fig. 4 suggests that, gulfwide, interannual variability in the depth of the winter mixed layer would be best described by a 2-component model whereby the firstorder component represents the distribution of $T_{\min }$ for each year, and the second-order component the annual average $Z_{0}$. The first-order component of the model was obtained by computing the relative frequency of cold profiles $\left(W_{i}\right)$ as:

$$
W_{i}=n_{i} / N_{i}
$$

where $N_{i}$ represents total number of temperature profiles with a well-defined CIL for Year $i$, and $n_{i}$ the number of temperature profiles with a well-defined CIL but with $T_{\min }$ lower or equal to $0.0^{\circ} \mathrm{C}$ for that same year. Fig. 5 shows the $W_{i}$ time series for the period 1947 to 2000 . 


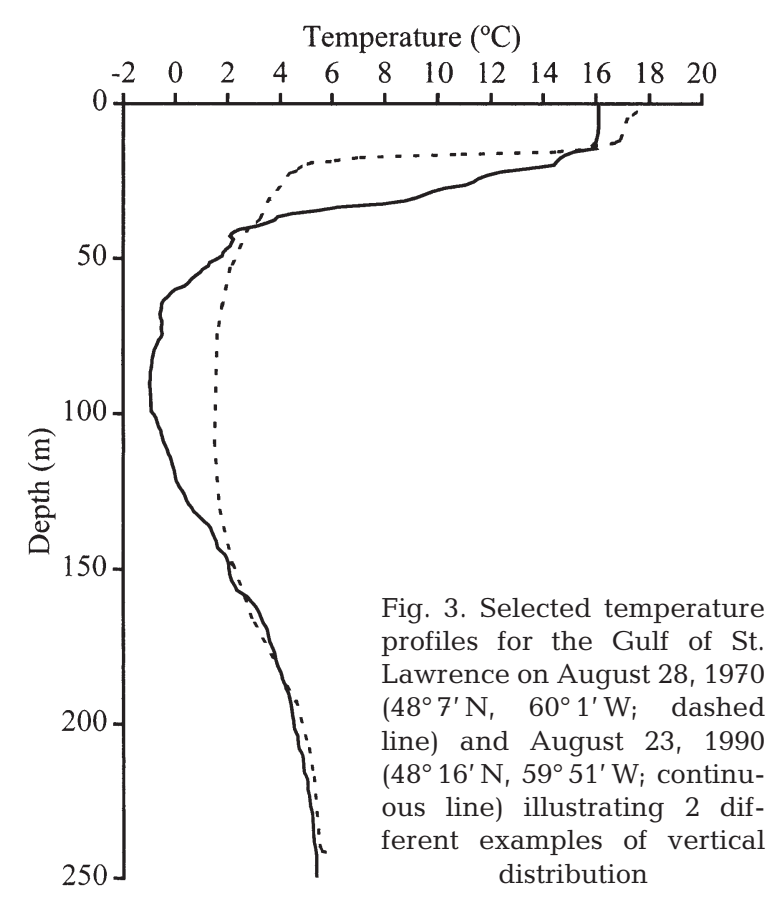

The second-order component of the model was obtained by extracting the individual $Z_{0}$ observations from all profiles with a well-defined CIL of $T_{\min } \leq 0.0^{\circ} \mathrm{C}$. Fig. 6 shows the resulting time series of $Z_{0}$ for the period 1947 to 2000. Over this $54 \mathrm{yr}$ time series, most $Z_{0}$ occurred between 75.4 and $106.3 \mathrm{~m}$ (25th and 75th percentiles, respectively), with a mean value of $91.1 \mathrm{~m}$.

The product of the 2 components in the model provided annually weighted estimates of the depth of the winter mixed layer $\left(Z_{\mathrm{W}}\right)$ as follows:

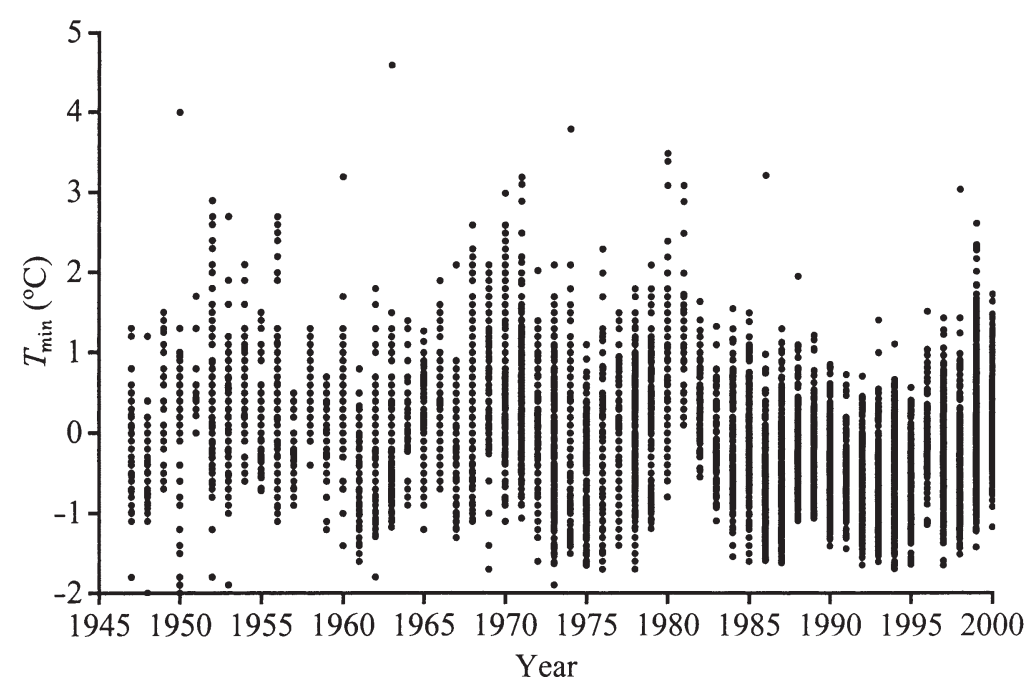

Fig. 4. Time series of minimum temperature $\left(T_{\min }\right)$ for profiles with a welldefined cold intermediate layer. Here and in Figs. 6, 7, 9 \& 11 data points represent range of observations during individual years (1947-2000)

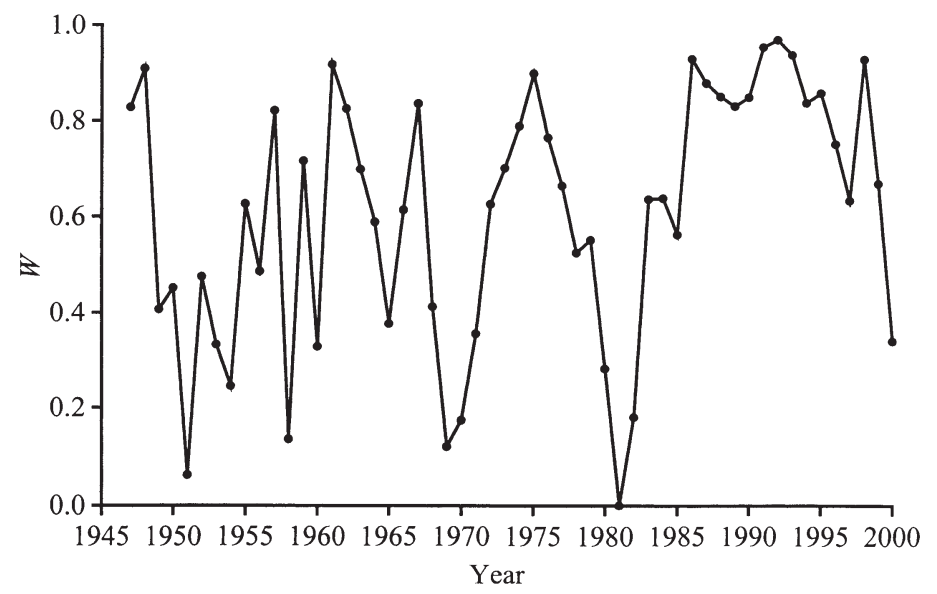

Fig. 5. Time series of frequency of cold-temperature profiles $(W)$

$$
Z_{\mathrm{W}}=W_{i} \times Z_{0}
$$

where $Z_{0}$ is in meters and $W_{i}$ is unitless. The time series of $Z_{\mathrm{W}}$ for the period 1947 to 2000 is shown in Fig. 7, and suggests the existence of large interannual variability. It is obvious that the resulting time series is strongly affected by the $W_{i}$ series. This is important, since the $W_{i}$ provides a gulf-wide relative contribution to each individual $Z_{0}$. For instance, assume a averaged $Z_{0}$ value of $90 \mathrm{~m}$ for 2 distinct years for which the same number of temperature profiles was collected. Obviously, this average value will not have the same relative weight for a year in which $Z_{0}$ is derived from $5 \%$ of the profiles with a well-defined CIL as for a year in which it is derived from $95 \%$ of the profiles. The weighting factor $W_{i}$ accounts for these interannual differences, and the time series of $Z_{\mathrm{W}}$ thus represents a time series of 'estimated depths' of the winter mixed layer for the Gulf of St. Lawrence. This point is discussed further below.

\section{Time series of spring nitrate concentration}

We attempted to find a way in which the time series for the depth of the winter mixed layer could be used to produce a time series of spring nitrate concentration in the surface waters. We assumed that the spring nitrate concentration in the surface layer could be derived from knowledge of the nitrate concentration at intermediate depths in November and of the depth of the winter mixed layer. Since a strong vertical gradient of nitrate concentration usually exists at intermediate depths in the GSL (Fig. 8), it is obvious that the spring nitrate concentration will strongly depend on the depth of the winter 


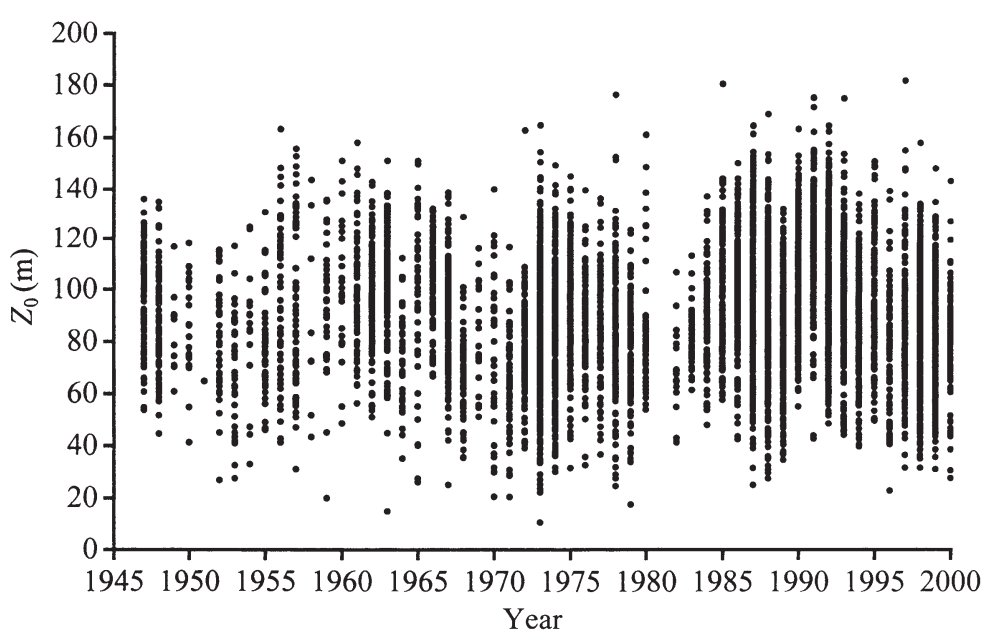

Fig. 6. Time series of greatest depth of $0^{\circ} \mathrm{C}$ isotherm $\left(Z_{0}\right)$

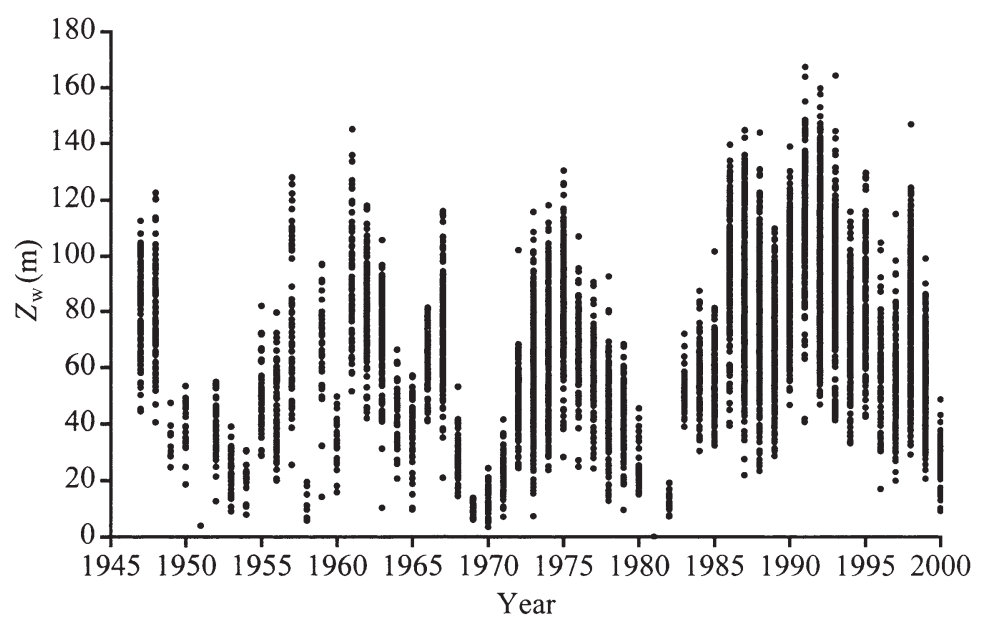

Fig. 7. Time series of annually weighted estimates of depth of winter mixed layer $\left(Z_{\mathrm{W}}\right)$

mixed layer-a deeper winter mixed layer implying higher nitrate concentrations. By combining Eqs. (1) \& (3), we were able to construct a time series of 'estimated' nitrate concentration $\left(\mathrm{NO}_{3}\right)$ for the surface layer of the GSL in spring as follows:

$$
\begin{aligned}
\mathrm{NO} 3= & W_{i}\left(-43.6087+0.0876 Z_{0}\right. \\
& -0.5758 \text { longitude }+0.2035 \text { latitude })
\end{aligned}
$$

where $\mathrm{NO}_{3}$ is in $\mu \mathrm{M}, Z_{0}$ in $\mathrm{m}$, longitude in ${ }^{\circ} \mathrm{W}$ and latitude in ${ }^{\circ} \mathrm{N}$.

Fig. 9 shows the resulting time series for estimated nitrate concentrations in the GSL, which suggests the existence of a significant interannual variability of 1 order of magnitude. The annual average of these estimated nitrate concentrations varied between $\sim 0.0$ and $12.5 \mu \mathrm{M}$, with an overall mean of $6.5 \mu \mathrm{M}$. These fluctuations were, however, not randomly distributed over

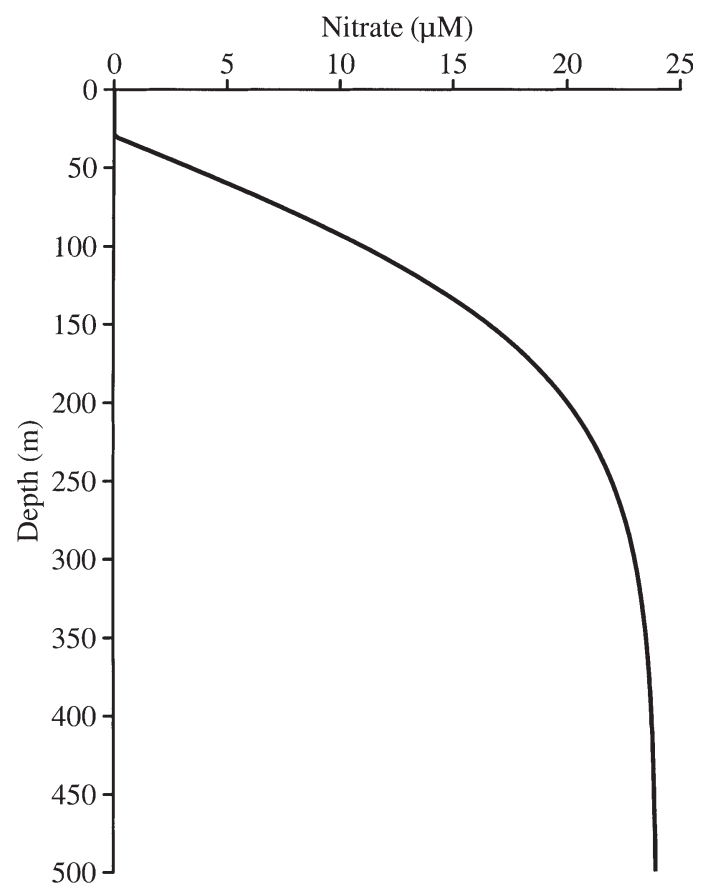

Fig. 8. Average nitrate profile in summer in the Gulf of St. Lawrence showing strong gradient of nitrateconcentration at intermediate depth

the $54 \mathrm{yr}$ of the time series. The nitrate time series was characterized by a coherent succession of alternating periods of low and high nitrate concentrations. Periods of low nitrate concentration would correspond to a warm state of the CIL (weak winter convection) and periods of high nitrate concentration to a cold state (strong winter convection), reflecting the general climate variability in the GSL. Over the last 3 decades, 3 warm periods with estimated nitrate concentrations well below the overall mean (1968 to 1972, 1977 to 1985 and 2000), and 2 cold periods (1973 to 1976 and 1986 to 1999) were identified. Fig. 10 suggests that for this same period of time, the annual average nitrate concentrations in the mixed layer was significantly related (Pearson's correlation coefficient $\mathrm{R}=0.65, \mathrm{p}<0.0001$ ) to the ice index of Drinkwater et al. (2003), which is itself significantly related to the winter air temperature. The implication of this finding is that a relationship between winter convection and ice formation probably exists.

\section{DISCUSSION}

This paper presents an analysis based on all existing (or available) historical nitrate and temperature data for the Gulf of St. Lawrence for the period 1947 to 2000. The main objective of this analysis was to construct the 


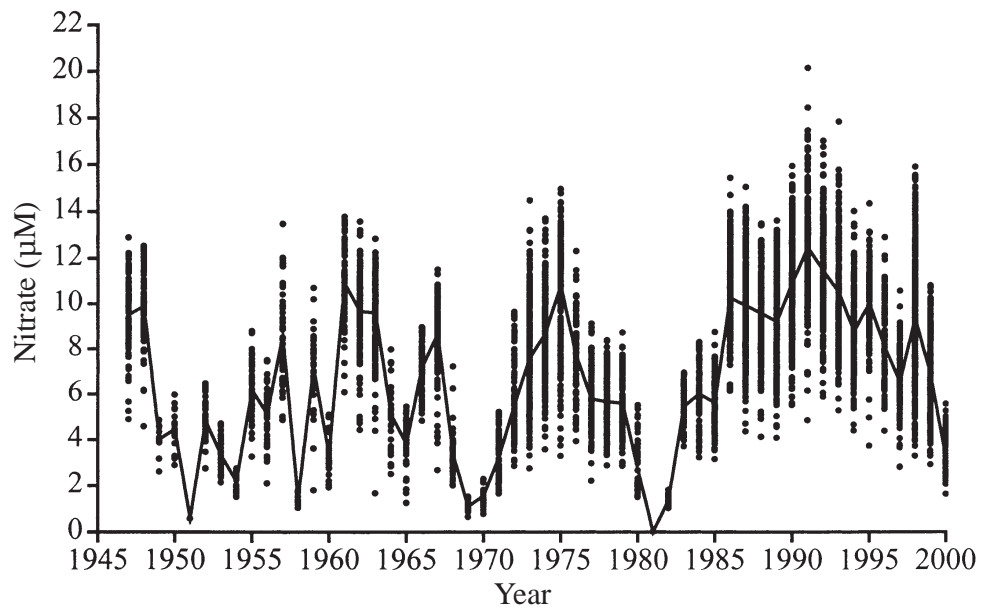

Fig. 9. Time series of estimated nitrate concentration in surface layer. Continuous line: annual average concentration

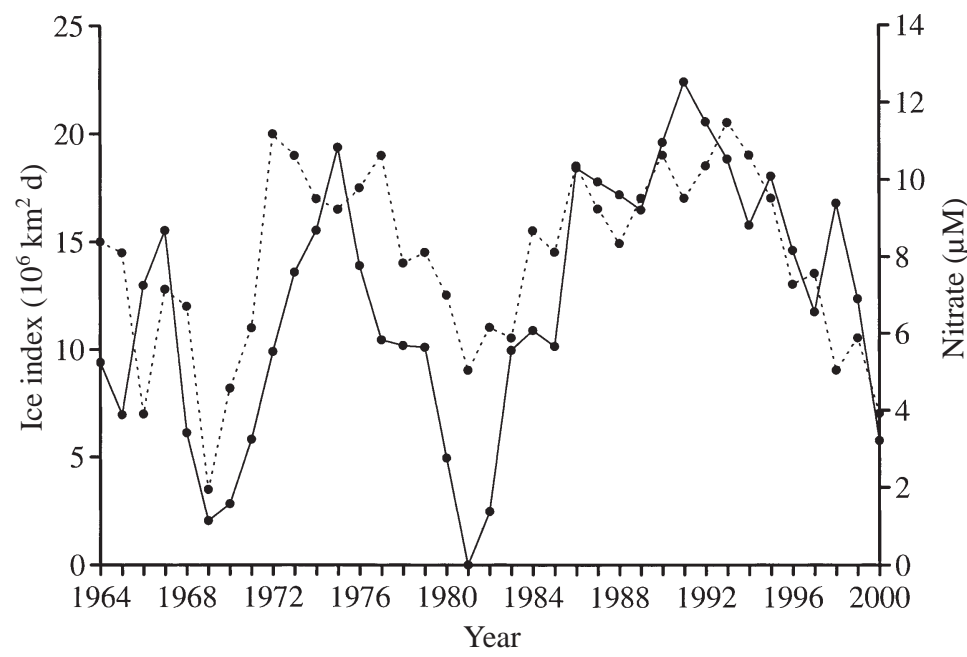

Fig. 10. Time series of estimated nitrate concentration in surface layer of the Gulf of St. Lawrence (continuous line) and ice index (dashed line) of Drinkwater et al. (2003)

longest possible retrospective time series of nitrate concentrations for the surface mixed layer in the latewinter-early-spring period, before the occurrence of the spring bloom of phytoplankton. We were rapidly confronted with limitations inherent in the historical databases available, and had to make rational choices. These choices are discussed below, but we will first clearly describe our original intention in this study.

\section{Original intention}

The 2 basic results of our analysis of the historical data sets are (1) a linear model describing the spatiotemporal distribution of nitrates in the intermediate layer (Eq. 1), and (2) a time series of the minimum tem- perature $\left(T_{\min }\right)$ for all profiles with a well-defined CIL (i.e. Fig. 4). Close examination of the database and our interpretation of the interannual variability in the $T_{\min }$ time series led us to develop a method to infer or estimate the depth of the winter mixed layer $\left(Z_{\mathrm{W}}\right)$ using the information for all profiles/years in which a welldefined cold intermediate layer was observed. This time series of $Z_{\mathrm{W}}$ was then used in conjunction with the linear model describing the nitrate concentrations (Eq. 1) to produce a time series of estimated nitrate concentrations for the latewinter-early-spring period, before the occurrence of the phytoplankton bloom. The final nitrate time series and the $Z_{\mathrm{W}}$ time series from which it is derived thus represent the actual 'hypothetic or estimated' time series.

\section{Limitations of databases}

Fig. 4 presents the basic results of our study. It is necessary to discuss further the limitations of the time series of $T_{\min }$ for those profiles with a welldefined CIL. First, the main limitation to the databases is the fact that the GSL has been historically undersampled, both in time and space. Although the relative importance of this limitation increases as the length of the time series increases, the usefulness of the time series also greatly increases (e.g. Brander et al. 2003). Second, the routine measurements in the GSL have changed during the period considered, as new sampling programs and gears became available. These limitations had to be overcome to construct an adequate time series for the period 1947 to 2000 .

As a first step in the development of our model, we assembled all available temperature and salinity data from the Bedford Institute and the Maurice Lamontagne Institute. An obvious way to validate the model would have been simply to compare the predicted and the observed winter mixing depths; this would merely require a good set of CTD profiles (temperature, salinity and density - since density is necessary to precisely assess the depth of the mixed layer) collected at the end of winter (i.e. March) during adequate gulf-wide surveys. However, a thorough search of the database showed that no such data set simply exists. In fact, we found a total of only 223 vertical temperature profiles collected in March within the whole domain of the model. Of these, 64 profiles had a well-defined CIL (based on the criteria developed in this study) and of these again, only 39 had concurrent salinity measurements. This was not sufficient to construct an adequate time series for the period 1947 to 2000. 
To overcome this lack of data at the end of the winter period, we developed a way to use the more numerous summer profiles, assuming that it was possible to infer the depth of the winter mixed layer from summer temperatures alone. The rationale behind our approach was that the relative importance of the CIL (depth range) would strongly depend on the previous winter mixing processes, and that this relative relationship should be maintained throughout the summer months. We acknowledge that a proportional or equal contribution from all subareas of the GSL and from each month between May and November would have produced an even more coherent $T_{\min }$ time series, but again this was impossible with the existing historical data. This was another limitation with which we had to deal. For example, Fig. 11 shows the time series of $T_{\min }$ for May (Fig. 11a), August (Fig. 11b) and November (Fig. 11c). The results indicate that a continuous time series for the period 1947 to 2000 cannot be constructed from data for any single month alone (this was confirmed by the the data for all other months between May and November; data not shown). On the other hand, we found evidence in the database indicating that the CIL is eroded from spring to fall. We do not think, however, that erosion alone can explain the significant interannual variability in $T_{\min }$ observed (e.g.) in May (Fig. 11a). It is of interest that a coherent interannual variability is apparent between months in the monthly time series in Fig. 11. Interannual variability in erosion can not be completely ignored, but Fig. 10 suggests that interannual differences in the formation of the CIL waters is most probably the dominant factor explaining interannual variability. Finally, there was also a potential contribution of sampling location (space) to the total variability in the $T_{\min }$ series, but again it was not possible from the available data to correct statistically for this factor. Despite all these limitations, we felt that our thorough analysis and the known reliability of the data used enabled inferences on the depth of the winter mixed layer for all years of the data series.

\section{Further considerations}

Another consideration is our choice of the greatest depth of the $0^{\circ} \mathrm{C}$ isotherm $\left(Z_{0}\right)$ to estimate the depth of the winter mixed layer. The $0^{\circ} \mathrm{C}$ isotherm is commonly used to define the CIL in the NW Atlantic (e.g. Drinkwater 1996), and is also consistent with the average $T_{\min }$ value of $-0.21^{\circ} \mathrm{C}$ recorded for the period 1947 to 2000 . We used the variability around this mean to infer vertical winter mixing. What would have been the results had we used another isotherm? Keeping in mind that we used a 2-component model to infer the depth of the winter mixed layer (Eq. 3), the data in
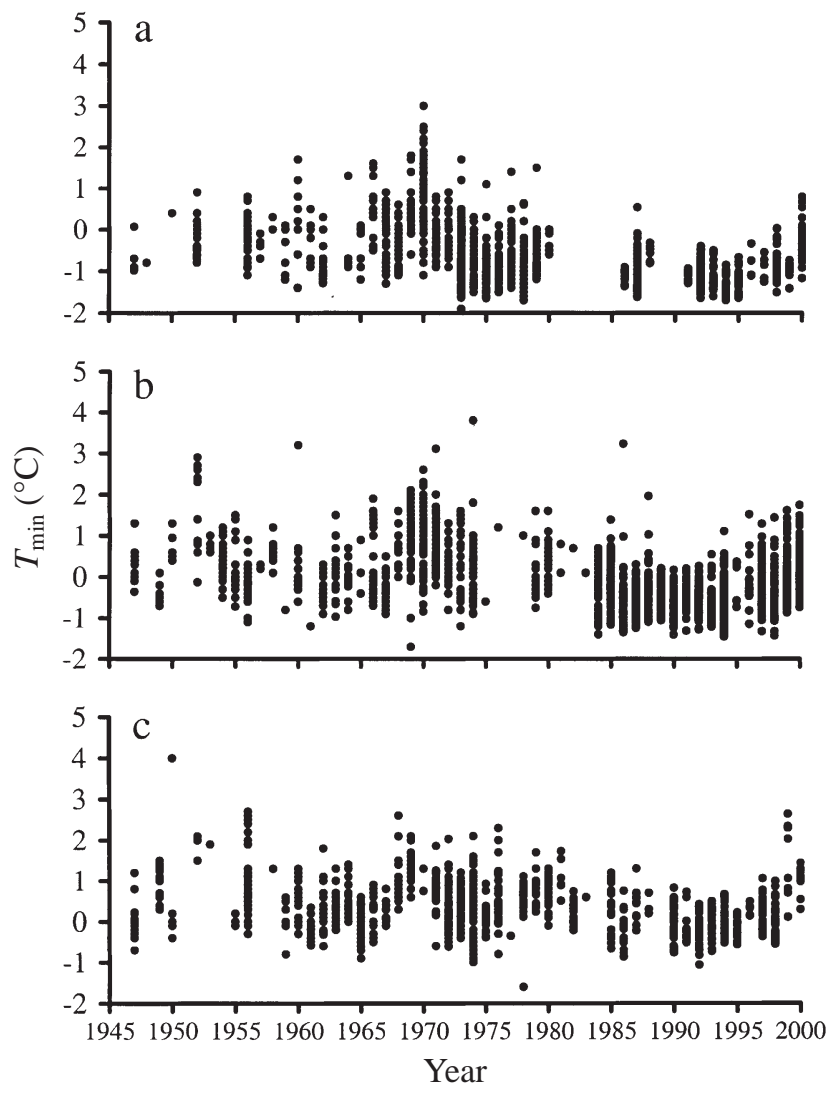

Fig. 11. Time series of minimum temperature $\left(T_{\min }\right)$ for temperature profiles with a well-defined cold intermediate layer in months of (a) May, (b) August and (c) November

Fig. 4 make this clear. Use of a temperature close to freezing point (e.g. $Z_{-1.8}$ ) would have severely restricted the number of observations for the secondorder component $\left(Z_{\mathrm{n}}\right)$, leading to a nearly constant first-order component, since most temperature profiles would have been too high to detect $\mathrm{Z}_{-1.8}$. On the other hand, use of a temperature above $0^{\circ} \mathrm{C}$ (say $2^{\circ} \mathrm{C}$ ) would have severely weakened the value of the second-order component, because the number of available profiles would again have been severely reduced (a deeper profile would be necessary to detect $Z_{2}$ than to detect $Z_{0}$ ). Therefore, we concluded that the $0^{\circ} \mathrm{C}$ isotherm was the most appropriate for infering the depth of the winter mixed layer from summer temperature profiles.

In some years, a large number of the available temperature profiles with a well-defined CIL were too high to allow detection of $Z_{0}$ (Fig. 3). Nevertheless these profiles contained important data that could be used in constructing the time series data (Figs. $4 \& 11$ ), and we were able to include this information in our calculation of the depth of the winter mixed layer by applying a weighting factor, $W_{i}$. This weighting factor (the first-order component in the model) provided us with a first approximation of the relative depth of win- 
ter mixing. Our problem was the absence of specific observations for a variable, not the absence of information per se. We believe that the fact that a given isotherm $\left(0,-0.5,-1^{\circ} \mathrm{C}\right.$, etc. $)$ is present in some years and absent in others in profiles with a well-defined CIL, must be significant. Fig. 6 shows that in some years, there were no (or very few) observations of $Z_{0}$, despite the presence of a significant number of profiles with a well-defined CIL (see $T_{\min }$ in Fig. 4). In 1981, for example, $W_{\text {i }}$ was clearly influenced by the fact that most profiles available for that year were collected between August and November. However, as stated in the foregoing subsection, we do not believe that erosion alone can explain these interannual differences; consequently, there was probably a very low nitrate concentration in the surface layer of the GSL in spring 1981. In addition, some of the profiles recorded in August or November during the period 1947 to 2000 had a $T_{\min }$ value $<0^{\circ} \mathrm{C}$, and sone of the profiles recorded in May had a $T_{\min }$ value $>0^{\circ} \mathrm{C}$ (Fig. 11).

\section{Testing validity of estimated time series}

Is the interannual variability observed in both the $Z_{\mathrm{W}}$ and the nitrate time series realistic? As mentioned before, very few concurrent temperature and salinity profiles were available for the end of the winter period (i.e. March) in the available database. Similarly, there were 14045 discrete nitrate observations within the model domain of our study, but of these, only 130 observations were in the surface layer (0 to $30 \mathrm{~m}$ ) during March, and the spatial variability associated with these data precluded testing the validity of our estimated time series of nitrate concentrations in early spring in the GSL. A simple way to validate our estimated time series would have been to compare the observed and estimated nitrate data for cold and warm years. But again, adequate discrete nitrate observations did not exist in the historical database. The validity of our estimated nitrate data series will therefore need to be tested in future years. To provide unequivocal evidence of the low-frequency variability suggested by our study, future data will also have to include years that represent cold and warm climate states in the GSL. Such validation may be possible in the near future using current nutrient observations at stations with a fixed position in the GSL (Atlantic Zone Monitoring Program: Therriault et al. 1998).

Other elements also need to be taken into account in any future attempt to test the validity of our estimated nitrate time series. First, nitrate concentrations in our study were estimated in Eq. (4) from individual $Z_{0}$ observations under the assumption that nitrate concentrations at the surface and at depth $Z_{0}$ have the same value because of uniform distribution in the surface mixed layer. This assumption was made to keep the model as simple as possible, but it obviously led to overestimation of nitrate concentration in the earlyspring surface layer, since the basic mass-conservation principle was not adhered to in our analysis: we did not adjust for the fact that an increase in nitrate concentration in the surface mixed layer following an input of higher nitrate concentration from deeper depths would lead to a redistribution of nitrate throughout the entire mixed layer. However, since the nitrate time series largely reflects interannual variability in the frequency of cold-temperature profiles (Figs. 5 \& 9), it seems reasonable to postulate that any such over-estimation should have a marginal effect on the relative magnitude of the variability in the nitrate time series.

A further consideration is that spring nitrate concentrations in the surface layer are not a conservative property of seawater: nitrates in the surface layer are rapidly depleted at the onset of the spring phytoplankton bloom, and nitrate uptake by the phytoplankton in the euphotic zone is a process which varies in both time and space. This factor adds to the complexity of testing the validity of the present model by means of nitrate observations in the surface layer at discrete stations, since validation observations may be biased by biological nutrient-uptake processes. We need to ensure that the low nitrate levels seemingly associated with a warm state of the CIL are not a consequence of nutrient utilization by phytoplankton. In this context (using March data as an example), assuming that the spring phytoplankton bloom had not yet occurred is not a guarantee of adequate data since phytoplankton growth has been observed on a number of occasions in the GSL during winter time also (e.g. Savenkoff et al. 2000). The best way to validate the nitrate time series would be to follow the changes in nitrate concentrations at intermediate depths under the euphotic zone at fixed stations, under the assumption that interannual changes in spring nitrate concentrations in the surface layer would proportionally match the changes at these intermediate depths.

Finally, many other physical processes, such as tidal mixing and freshwater runoff, can have a significant influence on the vertical advection of nitrates in the GSL. The present study suggests that winter convection, which is presumed to be spatially uniform over the whole GSL, is a major contributing factor to the interannual variability in nitrate abundance, but that the relative contribution of other processes exhibiting strong spatial variability should also be considered in any attempt to validate the nitrate time series. In this context, the recent development of a 3-dimensional hydrodynamic model for the GSL (Saucier et al. 2003) may provide a useful tool to achieve this goal. 


\section{Potential significance of interannual variability in spring nitrate availability}

Long time series of relevant properties of the marine environment are needed to clarify questions related to the fluctuations in the productivity of marine ecosystems, particularly in the context of climate changes and variability, a major concern of modern oceanographers. When available, hindcasts of these properties derived from existing historical data will significantly improve our understanding of information provided by new sampling programs and modern tools. The present study assumes that the links between winter convection, vertical advection of nitrate and primary production are key elements to understand the ecosystem productivity of the Gulf of St. Lawrence.

Cullen et al. (1992) indicated that changes in species succession can be the primary response of phytoplankton to environmental changes at geographical or longterm temporal scales. That interannual nitrate variability will result in significant changes in the state of a system is therefore widely recognized. For the GSL we can speculate that, in the regions where winter convection is a dominant factor in the vertical advection of nitrate, a variation of $\sim 1$ order of magnitude in nutrient availability will generate a clear shift between oligothrophic and eutrophic states of the pelagic ecosystem. Warm winters would thus be associated with thin ice cover (or ice formation) implying weak winter convection and low nitrate replenishment (as suggested by Fig. 10). The biological system would probably respond with a low phytoplankton bloom and weak sedimentation, and a dominance of pelagic flagellates. Cold winters would be associated with thick ice cover, high winter convection, high nitrate replenishment, a high spring phytoplankton bloom, strong sedimentation, and a dominance of diatoms. Significant interannual changes in spring nitrate concentrations of $\sim 1$ order of magnitude (as suggested by the present study) would thus be reflected in significant interannual variability in primary production processes (phytoplankton levels and species composition/succession) in the Gulf of St. Lawrence. Since the available food largely depends on the photosynthetic productivity of phytoplankton, the variability in phytoplankton productivity would be reflected in other trophic levels in this system. Therefore, understanding the mechanisms associated with low-frequency environmental fluctuations such as those observed in this study is essential to determine what processes govern the natural variability in the abundance of marine resources (Wooster \& Bailey 1989, Mann 1993). Future studies in the GSL should be directed toward a fundamental understanding of these various processes.
Acknowledgements. We are indebted to all scientists who contributed to the collection and the maintenance of the various databases used in this study. In particular, we wish to thank Peter Strain, Ken Drinkwater and Jean Landry, who kindly provided data. We would also like to thank François-J. Saucier and 3 anonymous referees for their very valuable comments on earlier versions of this paper.

\section{LITERATURE CITED}

Banks RE (1966) The cold layer in the Gulf of St. Lawrence. J Geophys Res 71:1603-1610

Barber RT (1992) Geologic and climatic time scales of nutrient variability. In: Falkowski PG, Woodhead AD (eds) Primary productivity and biogeochemical cycles in the sea. Plenum Press, New York, p 89-106

Brander KM, Dickson RR, Edwards M (2003) Use of continuous plankton recorder information in support of marine management: applications in fisheries, environmental protection, and in the study of ecosystem response to environmental change. Prog Oceanogr 58:175-191

Bugden GL, Hargrave BT, Sinclair MM, Tang CL, Therriault JC, Yeats PA (1981) Freshwater runoff effects in the marine environment: the Gulf of St. Lawrence example. Can Tech Rep Fish Aquat Sci 1078

Cullen JJ, Yang X, MacIntyre HL (1992) Nutrient limitation of marine photosynthesis. In: Falkowski PG, Woodhead AD (eds) Primary productivity and biogeochemical cycles in the sea. Plenum Press, New York, p 69-88

Drinkwater KF (1996) Atmospheric and oceanic variability in the Northwest Atlantic during the 1980s and early 1990s. J Northwest Atl Fish Sci 18:77-97

Drinkwater KF, Petrie B, Pettipas RG, Petrie WM (2003) An overview of meteorological, sea ice and sea-surface temperature conditions in Eastern Canada during 2002 (NAFO SCR Doc. 03/30 N4845). Northwest Atlantic Fisheries Organization, Dartmouth, NS

Dugdale R, Wilkerson F (1992) Nutrient limitation of new production in the sea. In: Falkowski PG, Woodhead AD (eds) Primary productivity and biogeochemical cycles in the sea. Plenum Press, New York, p 107-122

Gilbert D, Pettigrew B (1997) Interannual variability (19481994) of the CIL core temperature in the Gulf of St. Lawrence. Can J Fish Aquat Sci 54(Suppl 1):57-67

Koutitonsky VG, Budgen GL (1991) The physical oceanography of the Gulf of St. Lawrence: a review with emphasis on the synoptic variability of the motion. Can Spec Publ Fish Aquat Sci 113:57-90

Mann KH (1993) Physical oceanography, food chains, and fish stocks: a review. ICES J Mar Sci 50:105-119

Nicholls KH (1998) El Niño, ice cover, and Great Lakes phosphorus: implications for climate warming. Limnol Oceanogr 43:715-719

Petrie B, Yeats P (2000) Annual and interannual variability of nutrients and their estimated fluxes in the Scotian ShelfGulf of Maine region. Can J Fish Aquat Sci 57:2536-2546

Petrie B, Drinkwater K, Sandström A, Pettipas R, Gregory D, Gilbert D, Sekhon P (1996) Temperature, salinity and sigma-t atlas for the Gulf of St. Lawrence. Can Tech Rep Hydrogr Ocean Sci 178

Platt T, Harrison WG, Lewis MR, Li WKW, Sathyendranath S, Smith RE, Vezina AF (1989) Biological production of the oceans: the case for a consensus. Mar Ecol Prog Ser 52: $77-88$

SAS Institute (1991) SAS $^{\circledR}$ system for regression, 2nd edn. SAS Institute, Cary, NC 
Saucier FJ, Roy F, Gilbert D, Pellerin P, Ritchie H (2003) The formation and circulation processes of water masses and sea-ice in the Gulf of St. Lawrence. J Geophys Res 108: $1-20$

Savenkoff C, Vézina AF, Roy S, Klein B and 7 others (2000) Export of biogenic carbon and structure and dynamics of the pelagic food web in the Gulf of St. Lawrence. Part 1. Seasonal variations. Deep-Sea Res II 47:585-607

Steven DM (1974) Primary and secondary production in the Gulf of St. Lawrence. McGill Univ Montreal Mar Sci Cent Manuscr Rep 26

Stevens J (1992) Applied multivariate statistics for the social sciences, 2nd edn. Lawrence Erlbaum Associates, Hillsdale, NJ

Strain PM (1988) Chemical oceanography in the Gulf: pre-

Editorial responsibility: Otto Kinne (Editor),

Oldendorf/Luhe, Germany sent and future. Can Bull Fish Aquat Sci 220:159-173

Therriault JC, Petrie B, Pepin P, Gagnon J and 8 others (1998) Proposal for a Northwest Atlantic zonal monitoring program. Can Tech Rep Hydrogr Ocean Sci 194

Therriault JC, Galbraith PS, Starr M, Harvey M (2002) Intrusions of Labrador Shelf waters into the Gulf of St. Lawrence and their potential influence on the plankton community and higher trophic levels. Bull Atl Zone Monit Progr Fish Oceans 2:12-15

Wooster WS, Bailey KM (1989) Recruitment of marine fishes revisited. Can Spec Publ Fish Aquat Sci 108: 153-159

Yeats PA (1988) Nutrients. Can Bull Fish Aquat Sci 220:29-48 Yentsch CS (1990) Estimates of 'new production' in the midNorth Atlantic. J Plankton Res 12:717-734

Submitted: June 25, 2003; Accepted: May 4, 2004

Proofs received from author(s): September 7, 2004 